\title{
Attempt to counteract stigmatization of obese persons. Effect of psychoeducation on the level of bias against obese persons
}

\author{
Małgorzata Obara-Gołębiowska
}

Department of Psychology of Development and Education, University of Warmia and Mazury, Olsztyn, Poland

Department of Obesity Management, United Municipal Hospital, Olsztyn, Poland

\begin{abstract}
Introduction: Weight-based discrimination involves negative labels and stereotypes that can lead to prejudice, unfair treatment and discrimination in various areas of life. The aim of the study was to assess the influence of an educational program related to obesity stigma reduction on the level of anti-fat prejudices among young people.
\end{abstract}

Material and methods: All participants of the study (152 female students) were divided into 6 groups of approximately 25 persons. Four two-hour psychoeducational classes were conducted in the groups. The subjects discussed in the classes were assumed to promote more tolerant attitudes towards persons with body mass index (BMI) > 25 . The applied research tool was the Anti-fat Attitudes Scale. The first measurement was performed before the workshop-lecture classes, and the second after completion of the classes.

Results: The conducted statistical analysis by means of Student's $t$-test for dependent samples showed a significantly lower result for the level of bias towards obese persons in the second measurement in comparison to the first one: $\mathrm{M} 1=2.19, \mathrm{SD}=0.96, \mathrm{M} 2=2.03, \mathrm{SD}=0.87, \mathrm{t}(151)=4.17, p<0.05$.

Conclusions: An educational intervention focused on the development of more tolerant, empathetic, and understanding attitudes towards obesity is an efficient way of reducing bias against persons with excessive weight.

Key words: obesity, stigmatization, discrimination, psychoeducation, anti-fat biases.

\section{Introduction}

Excessive body weight may significantly lower self-esteem and quality of life in the sense of social belonging. This results from widespread victimization of overweight people [1]. This problem has significantly intensified since the first study into discrimination against people with body mass index (BMI) higher than 30 (class I obesity) [2]. Recent research has demonstrated that in the United States, where obesity poses a significant problem, weight-based discrimination has risen by $66 \%$ in the past decade [3], and is now as prevalent as racial discrimination [4]. The dramatic increase in the population of overweight people seems to incite intolerant attitudes towards obesity. In some cases, the victims internalize the negative stereotype of a "fatty" and come to believe that discrimination against obese people is justified [5].
The weight stigma is very powerful, as demonstrated by the results of a study [6] in which $24 \%$ of surveyed women with $\mathrm{BMI}>30$ and $17 \%$ of men with $\mathrm{BMI}>30$ were willing to sacrifice three years of their lives to weigh less. Women would also prefer to remain childless rather than sacrifice their figure.

Weight-based discrimination involves negative labels and stereotypes that can lead to prejudice, unfair treatment and discrimination in various areas of life [7]. Common weight-based stereotypes are that obese people are lazy, incompetent, lack self-discipline, have poor willpower and poor personal hygiene [8]. Overweight people are discriminated and victimized in many different settings, including education, the workplace and health care [7]. They face contempt, verbal or physical abuse and social repression, becoming subject to isolation, neglect, ridicule and gossip [9]. People with BMI > 30, in partic-

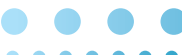

๑๑ 
Table 1. Level of bias towards obese persons before and after intervention

\begin{tabular}{|c|c|c|}
\hline & $\begin{array}{c}\text { Results before } \\
\text { intervention } \\
\text { (first measurement) }\end{array}$ & $\begin{array}{c}\text { Results after } \\
\text { intervention } \\
\text { (second measurement) }\end{array}$ \\
\hline M & 2.19 & 2.03 \\
\hline SD & 0.96 & 0.87 \\
\hline Min & 0.4 & 0.4 \\
\hline Max & 4.0 & 3.8 \\
\hline
\end{tabular}

ular women, find it more difficult to enter into romantic relationships [10].

The obesity stigma and the resulting discrimination lead to social isolation and contribute to devalued social identity of overweight people. Stress and low self-esteem increase the probability of emotional overeating and adopting a sedentary lifestyle. Those behaviors perpetuate obesity and create an additional risk of somatic disease caused by weight gain [7].

Due to the existing problem of obesity in Poland, and scarcity of research regarding social discrimination of persons with excessive weight, the objective of the study was to assess the influence of the educational program related to obesity stigma reduction on the level of anti-fat prejudices among young people.

\section{Material and methods}

The study group included 152 female students from the faculty of social sciences of the University of Warmia and Mazury in Olsztyn. The mean age of the students was 20.4, $\mathrm{SD}=0.54$.

The applied research tool was the Anti-fat Attitudes Scale (AFAS) by Morrison et al. [11]. The AFAS is an accurate and credible 5-item instrument developed to measure negative attitudes toward overweight individuals. The AFAS was subject to the translation process based on the consent of the authors. Moreover, the obtained results confirmed the credibility of the translated scale (Cronbach's a index $=0.751$ ). Respondents answered on the 5-degree scale and obtained for his or her answers a certain number of points: completely disagree ( 0 points), partially disagree (1 point), neither disagree nor agree ( 2 points), partially agree ( 3 points), totally agree (4 points). The Polish validation of the AFAS is not available yet. However, according to the original version of the AFAS [11], the range of points $0-1.2$ was interpreted as a low level of anti-fat bias, 1.3-2.7 as moderate and 2.8-4 as high.

Participants of the study were divided into 6 groups of approximately 25 persons. Four two-hour psychoedu-

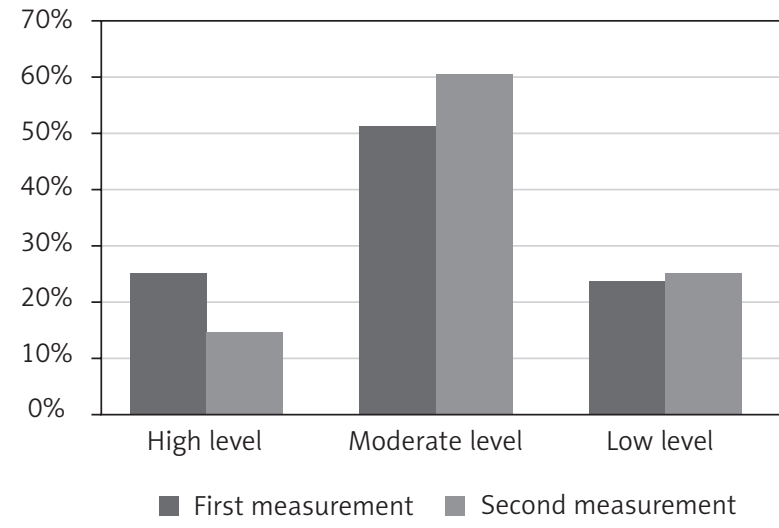

Figure 1. Level of bias towards obese persons before (first measurement) and after (second measurement) intervention

cational classes were conducted in the groups. The subjects discussed in the classes were assumed to promote a better understanding of the complex problem of obesity, and therefore development of more tolerant attitudes towards persons with BMI $>25$. They focused among other issues on the diversity of causes of overweight and obesity, among which factors were distinguished on which the patient has very limited or partial influence, e.g. biological, genetic, civilization, or family factors. The classes addressed the phenomenon of stigmatization of obesity, and its effect on the psychophysical and social condition, and on attempts to reduce body weight made by persons with excessive weight. Moreover, the students were given a task of conducting interviews with overweight and obese persons focused on the aforementioned subjects. The classes were of lecture-workshop character. The first measurement by means of the AFAS scale was performed before the workshop-lecture classes, and the second measurement was made three weeks later, i.e. after completion of the classes.

\section{Results}

The analysis of results employed the statistical software SPSS 22. The first measurement by means of the AFAS scale showed that $25 \%(n=38)$ of the persons obtained results suggesting a high level of anti-fat bias. $23.68 \%$ $(n=36)$ of the persons showed a low level of bias towards obese people. $51.32 \%(n=78)$ obtained a result suggesting a moderate level of anti-fat bias. In the second measurement, $14.47 \%(n=22)$ of persons obtained results suggesting a high level of anti-fat bias. $25 \%(n=38)$ of persons showed a low level of anti-fat bias. $60.53 \%(n=92)$ obtained a result suggesting a moderate level of anti-fat bias. In the first as well as the second measurement, the average result for bias towards obese persons in the analyzed group was at a moderate level. The statistical analysis conducted by means of Student's t-test for depen- 
dent samples, however, showed a significantly lower result for the level of bias towards obese persons in the second measurement in comparison to the first one: $\mathrm{M} 1=2.19$, $\mathrm{SD}=0.96, \mathrm{M} 2=2.03, \mathrm{SD}=0.87, \mathrm{t}(151)=4.17, p<0.05$.

\section{Discussion}

Obesity is a global-scale epidemic of the $21^{\text {st }}$ century. In Poland, every second adult is overweight, and one in six is obese [12]. Interventions in the scope of public health commonly focus on consequences of obesity related to physical health. Therefore, emphasis is put on the promotion of a healthy lifestyle as regards healthy eating and physical activity. Little attention is paid, however, to the psychosocial consequences resulting from obesity. One of these types of consequences is stigmatization and the resulting social discrimination of persons with excessive weight. Unfortunately, it is common to believe that stigmatization of obesity can be beneficial, because it motivates people to reduce their body weight. Previously published studies show, however, that the effect is opposite. Puhl [7] clearly indicates that the psychosocial consequences resulting from discrimination make the reduction of excessive weight more difficult. Moreover, the perception of the stigma of obesity as a motivating factor for a change of eating habits and physical activity results in an increase in the currently existing anti-fat bias. Without stigma-reduction interventions, obese people are left to cope with prejudice without assistance. Such a situation constitutes an additional burden in the process of body weight reduction, and therefore increases the probability of failure.

The present study involved an attempt to reduce bias against obese persons in a group of students. The applied intervention was based on psychoeducation of students regarding the diversity of causes of obesity, and promoting the awareness that some of the causes are not subject to control. The psychoeducation also emphasized discrediting the myth of stigmatization of obesity as a motivating factor for weight loss. The applied intervention aimed at the development of more empathetic, tolerant, and understanding attitudes towards obesity. The effects of the conducted workshop-lecture classes proved to be consistent with the assumptions, and included a considerable decrease in anti-fat prejudices towards obese people among the participants. The above findings are in accordance with the study of Gapinski et al. [13], who evidenced that educational interventions in society may to some extent reduce obesity bias. Similar research by Crandal [14] based on the attribution theory revealed that it is possible to improve attitudes toward obese people by educating participants about the biological, genetic, and uncontrollable reasons for obesity. Also research interventions by Wiese et al. [15] improved attitudes towards obese people by combining efforts to induce empathy and education about the uncontrollable causes of obesity.

\section{Conclusions}

The present study confirmed that an educational intervention focused on the development of more tolerant, empathetic, and understanding attitudes towards obesity is an efficient way of reducing bias against persons with excessive weight. The obtained results justified the practical application of education for the purpose of counteracting the phenomenon of stigmatization of obesity in society.

\section{Disclosure}

Author reports no conflict of interest.

\section{References}

1. Latner JD, O’Brien KS, Durse LE, et al. Weighing obesity stigma: the relative length of different forms of bias. Int J Obesity 2008; 32: 992-1000.

2. Falkner NH, French SA, Jeffrey RW, et al. Mistreatment due to weight: prevalence and sources of perceived mistreatment in woman and men. Obes Res 1999; 7: 572-576.

3. Andreyeva T, Puhl RM, Brownell KD. Changes in perceived weight discrimination among Americans: 1995-1996 through 2004-2006. Obesity 2008; 16: 1129-1134.

4. Man T, Tomiyama AJ, Westling E, et al. Medicare's search for effective obesity treatments. Am Psychol 2007; 62: 220-233.

5. Crocker J, Cornwell B, Major B. The stigma of overweight: affective consequences of attributional ambiguity. J Pers Soc Psychol 1993; 64: 60-70.

6. Garner DM. The body image survey results. Psychol Today 1997; 30: 30-47.

7. Puhl RM, Brownell KD. Psychosocial origins of obesity stigma: toward changing a powerful and pervasive bias. Obes Rev 2003; 4: 213-227.

8. Brylinsky JA, Moore JC. The identification of built stereotypes in young children. J Res Pers 1994; 28: 170-181.

9. Hussin M, Frazier S, Thompson JK. Fat stigmatization on YouTube: a content analysis. Body Image 2011; 8: 90-92.

10. Roehling PV. Fat is a Feminist Issue, but it is Complicated: Commentary on Fikkan and Rothbloom. Sex Roles 2012; 66: 593-599.

11. Morrison TG, O'Connor WE. Psychometric properties of a scale measuring negative attitudes toward overweight individuals. J Soc Psychol 1999; 139: 436-445.

12. GUS (Central Statistical Office), Health Condition of Polish Population in 2009 r., 2011r., www.stat.gov.pl/cps/rde/xbcr/gus/PUBL_ ZO_stan_zdrowia_2009.pdf, Warsaw 2011.

13. Gapinski KD, Schwartz MB, Brownell KD. Can television change anti-fat attitudes and behavior? J Appl Biobehav Res 2006; 11: 1-28.

14. Wiese HJ, Wilson JF, Jones RA, et al. Obesity stigma reduction in medical students. Int J Obesity 1992; 16: 859-868.

15. Crandal CS. Prejudice against fat people: ideology and self-interest. J Pers Soc Psychol 1994; 66: 882-894. 